Jurnal Sulolipu : Media Komunikasi Sivitas Akademika dan Masyarakat

Vol. 20 No. 12020

e-issn : 2622-6960, p-issn : 0854-624X

\title{
KEMAMPUAN LILIN ANTI NYAMUK DARI KULIT JERUK BALI (CITRUS MAXIMA) DALAM MEMATIKAN NYAMUK
}

Hasriani ${ }^{1}$ dan Ashari Rasjid²

1,2Jurusan Kesehatan Lingkungan Poltekkes Kemenkes Makassar

Email: hasrianiharis07@gmail.com

\begin{abstract}
The existence of mosquitoes in the community is very disturbing because of the behavior of mosquitoes that bite and also carry germs, such as dengue fever, malaria, chikungunya, and more. Especially during the rainy season, mosquitoes breed very rapidly. The purpose of this study was to determine the ability of grapefruit peel extract (citrus maxima) to eradicate mosquitoes. The type of study is a pure experiment (True experimental), is to determine the skin's ability grapefruit (Citrus maxima) as a mosquito repellent aromatherapy candles in kill mosquitoes. The population used in this study is the mosquitoes are moving on. The sample used in this study was 20 mosquitoes. Analysis of the table against the average mortality of mosquitoes with 3 times replication. The results showed that: Mosquito repellent wax from the skin of grapefruit with a concentration of $40 \%$ was able to kill mosquitoes by $25 \%$, at a concentration of $50 \%$ able to kill mosquitoes by $25 \%$, at a concentration of $60 \%$ able to kill mosquitoes by $40 \%$, at a concentration of $70 \%$ kill mosquitoes by $45 \%$, at a concentration of $80 \%$ can kill mosquitoes by $50 \%$. The conclusion was that there was no mosquito repellent from grapefruit skin which was able to kill the mosquitoes because it did not meet the criteria of lethal concentration of $50 \%$, all concentrations used were less than $L C_{50}$. It is recommended to increase the wax size so that the candle lights up longer and add the binding substance to the odor on the mosquito repellent candle is not evaporated quickly when used in a wider room.
\end{abstract}

Keywords: Skin Grapefruit, Mosquito Repellent candle, Mosquito.

\section{ABSTRAK}

Keberadaan nyamuk di lingkungan masyarakat sangatlah mengganggu, karena perilaku nyamuk yang menggigit dan juga membawa bibit penyakit, seperti demam berdarah, malaria, chikungunya, dan lainnya. Terutama pada musim penghujan, nyamuk berkembang biak dengan sangat pesat.Tujuan penelitian ini adalah Untuk mengetahui kemampuan ekstrak kulit jeruk bali (citrus maxima) untuk membasmi nyamuk. Adapun jenis penelitian yang digunakan adalah eksperimen murni (True eksperimental), yaitu untuk mengetahui kemampuan kulit jeruk bali (Citrus maxima) sebagai lilin aromaterapi anti nyamuk dalam mebunuh nyamuk. Populasi yang digunakan pada penelitian ini adalah nyamuk yang bergerak aktif. Sampel yang digunakan pada penelitian ini adalah 20 ekor nyamuk. Analisa dengan tabel terhadap rata-rata kematian nyamuk dengan 3 kali replikasi.Hasil penelitian menunjukkan bahwa: lilin anti nyamuk dari kulit jeruk bali dengan konsentrasi $40 \%$ mampu mematikan nyamuk sebesar 25\%, pada konsentrasi 50\% mampu mematikan nyamuk sebesar 25\%, pada konsentrasi $60 \%$ mampu mematikan nyamuk sebesar $40 \%$, pada konsentrasi $70 \%$ mampu mematikan nyamuk sebesar $45 \%$, pada konsentrasi $80 \%$ mampu mematikan nyamuk sebesar $50 \%$.Kesimpulan yang didapatkan yaitu lilin anti nyamuk dari kulit jeruk bali tidak ada yang mampu dalam mematikan nyamuk, karna tidak memenuhi kriteria lethal consentration $50 \%$, seluruh konsentrasi yang digunakan kurang dari $\mathrm{LC}_{50}$. Disarankan agar menambah ukuran lilin agar lilin menyala lebih lama dan menambahkan zat pengikat agar bau pada lilin anti nyamuk tidak menguap dengan cepat saat digunakan di ruangan yang lebih luas.

Kata Kunci: Kulit Jeruk Bali, Lilin Anti Nyamuk, Nyamuk.

\section{PENDAHULUAN}

Keberadaan nyamuk di lingkungan masyarakat sangatlah mengganggu, karena perilaku nyamuk yang menggigit dan juga membawa bibit penyakit, seperti demam berdarah, malaria, chikungunya, dan lainnya. Terutama pada musim penghujan, nyamuk berkembang biak dengan sangat pesat.

Nyamuk merupakan serangga yang banyak menimbulkan masalah bagi manusia. Selain gigitan dan dengungnya yang mengganggu, nyamuk merupakan vektor atau penular beberapa jenis panyakit berbahaya dan mematikan bagi manusia. Seperti demam berdarah, malaria, kaki gajah, dan chikungunya (Farida, 2008). Menurut Arixs (2008), berbagai penyakit disebar oleh tidak kurang dari 2.500 spesies nyamuk.

Kulit jeruk merupakan salah satu limbah yang banyak beredar di lingkungan. Limbah kulit jeruk dapat berasal dari industri minuman, ataupun dari pasar. Pada tahun 2013, jumlah kulit jeruk di Indonesia mencapai 309.678 ton tiap tahunnya. Sejauh ini belum banyak orang yang mampu memanfaatkan limbah kulit jeruk, khususnya limbah di pasar, agar menambah nilai jualnya.

Pada kulit jeruk bali juga terdapat minyak atsiri yang antara lain memiliki kandungan limonen $(95 \%)$, myrcene $(2 \%)$, noctanal $(1 \%)$, pinene $(0,4 \%)$, linanol $(0,3 \%)$, decanal $(0,3 \%)$, sabiene $(0,2 \%)$, geraniol $(0,1 \%)$, neral $(0,1 \%)$, dodecanal $(0,1 \%)$, dan Sitronela $(0,5 \%)$. (Adityo Kurniawan, 2008 dalam Andi Matoro Putra dkk, 2014).

\section{BAHAN DAN METODE}

\section{Lokasi Penelitian:}

Lokasi penelitian ini berlokasi di Jurusan Kesehatan Lingkungan Poltekkes Makassar, sedangkan pembuatan ekstrak kulit jeruk bali dibuat di Laboratorium Jurusan Kesehatan Lingkungan Poltekkes Makassar. 
Jurnal Sulolipu : Media Komunikasi Sivitas Akademika dan Masyarakat

Vol. 20 No. 12020

e-issn : 2622-6960, p-issn : 0854-624X

\section{DESAIN DAN VARIABEL PENELITIAN}

\section{a. Desain}

Penelitian ini bersifat eksperimen murni (True eksperimental), yaitu untuk mengetahui kemampuan kulit jeruk bali (Citrus maxima) sebagai lilin aromaterapi anti nyamuk dalam mebunuh nyamuk.

b. Variable Penelitian

1. Variabel bebas adalah yaitu lilin anti nyamuk kulit jeruk bali dengan konsentrasi $40 \%, 50 \%, 60 \%, 70 \%$, dan $80 \%$.

2. Variabel terikat adalah kemampuan lilin anti nyamuk dalam mematikan nyamuk.

3. Variabel pengganggu adalah suhu dan kelembapan.

\section{POPULASI DAN SAMPEL}

\section{a. Populasi}

Populasi yang digunakan pada penelitian ini adalah nyamuk yang bergerak aktif.

b. Sampel

Sampel yang digunakan pada penelitian ini adalah 20 ekor nyamuk.

\section{PENGUMPULAN DATA}

\section{a. Data Primer}

Data primer adalah data yang diperoleh berdasarkan hasil pengamatan langsung $\mathrm{di}$ laboratorium.

\section{b. Data Sekunder}

Data sekunder adalah data yang diperoleh dari berbagai referensi baik artikel-artikel, buku online dan buku non-online, internet, jurnal, dan studi kepustakaan yang dianggap mendukung teori yang ada serta dianggap memiliki keterkaitan dengan penelitian ini.

\section{c. Teknik Analisa Data}

Data yang diperoleh dari hasil pengamatan akan disajikan dalam bentuk tabel kemudian dianalisa secara deskriptif terhadap kematian nyamuk dengan konsentrasi berbeda-beda yang dibuat dalam bentuk lilin anti nyamuk.

\section{HASIL PENELITIAN}

Tabel 1

Hasil Pengamatan Nyamuk Yang Mati Setelah Pemaparan Dengan Konsentrasi $\mathbf{4 0} \%$ Lilin Anti Nyamuk Dari Kulit Jeruk Bali Setiap 1 Jam Pengamatan Selama 5 Jam Tahun 2019

\begin{tabular}{cccccc}
\hline No & Waktu & \multicolumn{3}{c}{$\begin{array}{c}\text { Jumlah Kematian } \\
\text { Nyamuk Setiap } \\
\text { Replikasi }\end{array}$} & Kontrol \\
& & P.1 & P.2 & P.3 & \\
1 & 1 Jam & 0 & 0 & 0 & 0 \\
2 & 2 Jam & 0 & 0 & 0 & 0 \\
3 & 3 Jam & 2 & 1 & 2 & 0 \\
4 & 4 Jam & 1 & 3 & 1 & 0 \\
5 & 5 Jam & 2 & 1 & 1 & 0 \\
& Total & 5 & 5 & 4 & 0 \\
\hline
\end{tabular}

Sumber: Data Primer.

Tabel 2

Hasil Pengamatan Nyamuk Yang Mati Setelah Pemaparan Dengan Konsentrasi 50\% Lilin Anti Nyamuk Dari Kulit Jeruk Bali Setiap 1 Jam Pengamatan Selama 5 Jam Tahun 2019

\begin{tabular}{|c|c|c|c|c|c|}
\hline \multirow[t]{2}{*}{ No } & \multirow[t]{2}{*}{ Waktu } & \multicolumn{3}{|c|}{$\begin{array}{c}\text { Jumlah Kematian } \\
\text { Nyamuk Setiap } \\
\text { Replikasi }\end{array}$} & \multirow[t]{2}{*}{ Kontrol } \\
\hline & & P.1 & P.2 & P.3 & \\
\hline 1 & 1 Jam & 0 & 0 & 0 & 0 \\
\hline 2 & 2 Jam & 1 & 0 & 0 & 0 \\
\hline 3 & 3 Jam & 1 & 1 & 1 & 0 \\
\hline 4 & $4 \mathrm{Jam}$ & 2 & 2 & 2 & 0 \\
\hline 5 & $5 \mathrm{Jam}$ & 2 & 2 & 2 & 0 \\
\hline \multicolumn{2}{|c|}{ Total } & 6 & 5 & 5 & 0 \\
\hline
\end{tabular}

Sumber: Data Primer.

Tabel 3

Hasil Pengamatan Nyamuk Yang Mati Setelah Pemaparan Dengan Konsentrasi 60\% Lilin Anti Nyamuk Dari Kulit Jeruk Bali Setiap 1 Jam Pengamatan Selama 5 Jam Tahun 2019

\begin{tabular}{cccccc}
\multicolumn{5}{c}{ Tahun 2019 } \\
No & Waktu & $\begin{array}{c}\text { Jumlah Kematian } \\
\text { Nyamuk Setiap } \\
\text { Replikasi }\end{array}$ & Kontrol \\
1 & P.1 & P.2 & P.3 & \\
2 & 2 Jam & 0 & 0 & 0 & 0 \\
3 & 1 & 1 & 1 & 0 \\
4 & 3 Jam & 2 & 1 & 2 & 0 \\
5 & 4 Jam & 3 & 3 & 3 & 0 \\
& Total & 1 & 2 & 2 & 0 \\
\hline Sumber: Data Primer. & 7 & 7 & 8 & 0 \\
\end{tabular}


Tabel 4

Hasil Pengamatan Nyamuk Yang Mati Setelah Pemaparan Dengan Konsentrasi 70\% Lilin Anti Nyamuk Dari Kulit Jeruk Bali Setiap 1 Jam Pengamatan Selama 5 Jam Tahun 2019

Jumlah Kematian

\begin{tabular}{|c|c|c|c|c|c|}
\hline \multirow{3}{*}{ No } & \multicolumn{5}{|c|}{ Jumlah Kematian } \\
\hline & Waktu & \multicolumn{3}{|c|}{$\begin{array}{l}\text { Nyamuk Setiap } \\
\text { Replikasi }\end{array}$} & Kontrol \\
\hline & & P. 1 & P. 2 & P.3 & \\
\hline 1. & $1 \mathrm{Jam}$ & 1 & 0 & 1 & 0 \\
\hline 2. & 2 Jam & 1 & 2 & 2 & 0 \\
\hline 3. & $3 \mathrm{Jam}$ & 2 & 1 & 1 & 0 \\
\hline 4. & $4 \mathrm{Jam}$ & 3 & 2 & 2 & 0 \\
\hline \multirow[t]{2}{*}{5.} & 5 Jam & 2 & 3 & 3 & 0 \\
\hline & Total & 9 & 10 & 9 & 0 \\
\hline
\end{tabular}

Sumber: Data Primer

Tabel 5

Hasil Pengamatan Nyamuk Yang Mati Setelah Pemaparan Dengan Konsentrasi 80\% Lilin Anti Nyamuk Dari Kulit Jeruk Bali Setiap 1 Jam Pengamatan Selama 5 Jam Tahun 2019

\begin{tabular}{|c|c|c|c|c|c|}
\hline \multirow[t]{2}{*}{ No } & \multicolumn{4}{|c|}{$\begin{array}{c}\text { Jumlah Kematian Nyamuk } \\
\text { Setiap Replikasi }\end{array}$} & \multirow[t]{2}{*}{ Kontrol } \\
\hline & & P.1 & P.2 & P.3 & \\
\hline 1 & $1 \mathrm{Jam}$ & 2 & 2 & 1 & 0 \\
\hline 2 & 2 Jam & 2 & 1 & 2 & 0 \\
\hline 3 & 3 Jam & 1 & 2 & 2 & 0 \\
\hline 4 & 4 Jam & 2 & 2 & 2 & 0 \\
\hline 5 & 5 Jam & 2 & 3 & 1 & 0 \\
\hline \multicolumn{2}{|c|}{ Total } & 9 & 10 & 8 & 0 \\
\hline
\end{tabular}

Sumber: Data Primer

\section{PEMBAHASAN}

Berdasarkan hasil penelitian yang telah dilakukan dengan menggunakan 5 konsentrasi yang berbeda- beda dan 1 kontrol, yaitu $40 \%$, $50 \%, 60 \%, 70 \%, 80 \%$, dan control selama 5 jam pengamatan dengan interval waktu 1 jam dengan jumlah sampel nyamuk sebanyak 20 ekor, diperoleh nyamuk yang mati pada waktu pemaparan yang berbeda-beda dari konsentrasi yang berbeda-beda pula. Pada kontrol terlihat bahwa tidak dijumpai adanya nyamuk yang mati. Hal ini membuktikan kondisi lingkungan yang terdapat dalam kurungan tidak mempengaruhi keberlangsungan hidup nyamuk tersebut.

Pada pemaparan konsentrasi $40 \%$ lilin anti nyamuk dari ekstrak kulit jeruk bali selama 5 jam pengamatan didapatkan rata-rata nyamuk uji yang mati sebanyak 5 ekor dengan persentase kematian sebanyak 25\%. Pada pemaparan konsentrasi $50 \%$ lilin anti nyamuk dari ekstrak kulit jeruk bali selama 5 jam pengamatan didapatkan rata-rata nyamuk uji yang mati sebanyak 5 ekor dengan persentase kematian sebanyak 25\%. Pada pemaparan konsentrasi $60 \%$ lilin anti nyamuk dari ekstrak kulit jeruk bali selama 5 jam pengamatan didapatkan rata-rata nyamuk uji yang mati sebanyak 8 ekor dengan persentase kematian sebanyak 40\%. Pada pemaparan konsentrasi $70 \%$ lilin anti nyamuk dari ekstrak kulit jeruk bali selama 5 jam pengamatan didapatkan rata-rata nyamuk uji yang mati sebanyak 9 ekor dengan persentase kematian sebanyak 45\%. Pada pemaparan konsentrasi $80 \%$ lilin anti nyamuk dari ekstrak kulit jeruk bali selama 5 jam pengamatan didapatkan rata-rata nyamuk uji yang mati sebanyak 10 ekor dengan persentase kematian sebanyak $50 \%$.

Dilihat pada tabel 5.1 sampai dengan tabel 5.4 adanya perbedaan kematian nyamuk uji berdasarkan interval waktu pemaparan. Hal ini menunjukkan lama waktu pemaparan berpengaruh terhadap kematian nyamuk uji, dimana semakin lama nyamuk uji terpapar dengan lilin anti nyamuk dari ekstrak kulit jeruk bali akan semakin mempengaruhi jumlah kematian nyamuk uji. Meski terdapat nyamuk uji yang mati dalam kotak percobaan, tapi lilin anti nyamuk dari kulit jeruk bali dengan konsentrasi $40 \%$, 50\%, $60 \%$, dan $70 \%$ dinyatakan tidak mampu dalam mematikan nyamuk uji dan tidak mencapai kriteria lethal consentration 50 ( $\mathrm{LC}_{50}$ ), karena nyamuk uji yang mati kurang dari $50 \%$. Pada tabel 5.5, lilin anti nyamuk dari kulit jeruk bali dengan konsentrasi $80 \%$ dinyatakan mampu dalam mematikan nyamuk uji dan mencapai kriteria lethal consentration 50 ( $\left.\mathrm{LC}_{50}\right)$, karena nyamuk uji yang mati 50\%. Sedangkan perlakuan pada kontrol tidak terdapat nyamuk yang mati sehngga hasil yang diperoleh dapat menggambarkan hasil yang sebenarnya.

Jika dibandingkan dengan penelitian sebelumnya oleh Nurul Hidayah, dkk, dengan metode losion membuktikan bahwa kulit jeruk bali dapat digunakan sebagai repelen terhadap nyamuk aedes aegypti dan efektif selama 1 jam. Juga dalam penelitian Kadek Haripriya Dewi, bahwa limbah kulit jeruk bali dalam bentuk spray dapat membunuh 10 nyamuk dalam 3 menit dengan konsentrasi 5 gram kulit jeruk bali dan di campur dengan $80 \mathrm{ml}$ air.

Pada penelitian tersebut dengan tujuan yang berbeda dimana pada metode lotion sudah efektif dalam waktu 1 jam dan pada metode spray dengan konsentrasi 5 gram sudah mampu membunuh nyamuk sebanyak 10 ekor dalam kurun waktu 3 menit, sedangkan pada penelitian ini ekstrak kulit jeruk bali yang dicampur dengan lilin lebah dinyatakan tidak sejalan dengan penelitian sebelumnya tentang ekstrak kulit jeruk bali, karena pada konsentrasi tertinggi yang digunakan yaitu $80 \%$ hanya bisa mematikan nyamuk uji sebanyak 10 ekor dalam kurun waktu 5 jam. Meski demikian, konsentrasi 80\% memenuhi kriteria lethal consentration $50\left(\mathrm{LC}_{50}\right)$. 
Dalam proses pembuatan ekstrak kulit jeruk bali, terjadi kesalahan dalam pembuatan pada ekstrak kulit jeruk bali. Konsentrasi ekstrak yang dibuat tidaklah $100 \%$, karena masih terdapat sisa methanol di dalamnya sehingga ekstrak yang diperoleh tidak kental atau berbentuk gel dan juga adanya kesalahan saat pencampuran ekstrak dengan lilin lebah. Perbandingan antara lilin lebah dengan ekstrak kulit jeruk bali tidak sesuai dengan rumus yang telah ditentukan, sehingga saat pengaplikasiannya pada nyamuk uji, lilin lebah yang telah bercampur dengan ekstrak kulit jeruk bali tidak mampu dalam mematikan nyamuk uji dalam kotak percobaan.

Kematian nyamuk uji disebabkan oleh senyawa aktif yang terdapat pada kulit jeruk bali, yaitu limonen, sitronela, linalool, dan geraniol senyawa-senyawa ini sangat tidak disukai nyamuk dan dapat mematikan bagi nyamuk. Kematian nyamuk disebabkan karena keracunan oleh senyawa-senyawa aktif yang terdapat pada kulit jeruk bali akibat aroma yang dikeluarkan dari hasil pembakaran lilin yang dicampur dengan ekstrak kulit jeruk bali dimana aroma tersebut menyengat dan tersebar keseluruh ruangan kotak percobaan hingga nyamuk uji yang berada dalam kotak percobaan tidak lagi mampu bertahan hidup.

Limonen merupakan senyawa yang terdapat pada kulit jeruk bali yang dapat merusak sistem pernapasan pada nyamuk atau serangga lainnya sehingga menyebabkan kematian, cara kerja dari limonen ini mirip dengan piretrin. Cara kerja piretrin adalah dengan dua tahap yaitu dengan meracuni serangga (knock down) kemudian mengganggu syaraf (blockade) serangga. Serangga biasanya lumpuh (knock down) tetapi dapat normal kembali bila tahap pertama bisa di atasi. Di sini, serangga tidak akan mati, tetapi bila serangga tidak bisa menetralkan tahap pertama maka jaringan syaraf akan terganggu dan akhirnya mati. Geraniol dan linanool merupakan senyawa yang tidak disukai nyamuk dan mampu mengusir nyamuk juga berfungsi sebagai penenang bagi manusia. Sitronella mempunyai sifat racun dehidrasi (Desiccant). Racun tersebut merupakan racun kontak yang dapat mengakibatkan kematian karena kehilangan cairan terus menerus. Serangga yang terkena racun ini akan mati karena kekurangan cairan.

Penggunaan insektisida alami memiliki keunggulan dan kelemahan yaitu insektisida nabati tidak atau hanya sedikit meninggalkan residu pada komponen lingkunan dan makanan sehingga dianggap lebih aman dari pada insektisida sintetis/kimia, zat pestisida dalam insektisida nabati lebih cepat terurai di alam sehingga tidak menimbulkan resistensi pada sasaran, dapat dibuat sendiri dengan cara sederhana, bahan membuat insektisida nabati dapat disediakan di sekitar rumah dan secara ekonomi tentunya akan mengurangi biaya pembelian insektisida.

Kelemahan penggunaan insektisida nabati, selain keunggulan insektisida nabati, tentunya kita tidak dapat mengesampingkan beberapa kelemahan pemakaian insektisida nabati tersebut kelemahannya antar lain insektisida nabati memeiliki bahan aktif yang kompleks (multiple activeingredient) dan kadang kala tidak dapat dideteksi dan tanaman insektisida nabati yang sama, tetapi tumbuh di tempat yang berbeda, iklim berbeda, jenis tanah yang berbeda, umur tanaman berbeda, dan waktu panen yang berbeda mengakibatkan bahan aktifnya menjadi bervariasi (Evi Naria, 2005).

Lilin anti nyamuk ini tidak terlalu efisien bila digunakan diruangan yang luas, karena bau khas kulit jeruk bali akan mudah menguap dengan cepat saat lilin dinyalakan, maka dari itu harus menggunakan zat pengikat, zat pengikat adalah suatu senyawa yang mempunyai daya menguap lebih rendah sehingga kecepatan penguapan dapat dikurangi atau dihambat. Menurut Ahmad Idris, dkk dalam penelitiannya tentang analisis kualitas minyak nilam (pogostemon cablin benth) produksi kabupaten buol, minyak nilam sangat baik digunakan sebagai zat pengikat, minyak nilam dapat bercampur dengan minyak atsiri yang lain, mudah larut dalam alkohol dan sukar menguap. Pada minyak nilam terdapat senyawa patchouli alkohol yang berfungsi sebagai bahan pengikat wewangian agar aroma keharumannya bertahan lebih lama.

\section{KESIMPULAN DAN SARAN}

\section{a. Kesimpulan}

1. Lilin anti nyamuk dari kulit jeruk bali (citrus maxima) dengan konsentrasi $40 \%$ dinyatakan tidak mampu dalam mematikan nyamuk, karna dilihat dari hasil penelitian dalam pengamatan selama 5 jam persentase kematian nyamuk hanya sebesar $25 \%$.

2. Lilin anti nyamuk dari kulit jeruk bali (citrus maxima) dengan konsentrasi $50 \%$ dinyatakan tidak mampu dalam mematikan nyamuk, karna dilihat dari hasil penelitian dalam pengamatan selama 5 jam persentase kematian nyamuk hanya sebesar $25 \%$.

3. Lilin anti nyamuk dari kulit jeruk bali (citrus maxima) dengan konsentrasi $60 \%$ dinyatakan tidak mampu dalam 
mematikan nyamuk, karna dilihat dari hasil penelitian dalam pengamatan selama 5 jam persentase kematian nyamuk hanya sebesar $40 \%$.

4. Lilin anti nyamuk dari kulit jeruk bali (citrus maxima) dengan konsentrasi $70 \%$ dinyatakan tidak mampu dalam mematikan nyamuk, karna dilihat dari hasil penelitian dalam pengamatan selama 5 jam persentase kematian nyamuk hanya sebesar $45 \%$.

5. Lilin anti nyamuk dari kulit jeruk bali (citrus maxima) dengan konsentrasi $80 \%$ dinyatakan mampu dalam mematikan nyamuk, karna dilihat dari hasil penelitian dalam pengamatan selama 5 jam persentase kematian nyamuk sebesar $50 \%$.

b. Saran

1. Untuk penelitian selanjutnya diharapkan bisa meningkatkan konsentrasi agar dapat memanuhi kriteri lethal consentration 50 ( $\left.\mathrm{LC}_{50}\right)$.

2. Menambah waktu pemaparan dengan cara menambah ukuran lilin agar lebih besar sehingga lilin bisa menyala lebih lama.

3. Menambahkan zat pengikat agar bau pada lilin anti nyamuk tidak menguap dengan cepat saat digunakan di ruangan yang lebih luas.

\section{DAFTAR PUSTAKA}

Adji Suranto. 2007. Terapi Madu. Jakarta: Niaga Swadaya. (online) https://books.google.co.id/books?id=dmuirXKmdBcC\&pg=PA101\&dq=lilin+lebah\&hl=id\&sa =X\&ved=0ahUKEwj0qMeVJ7fAhUHv48KhdKrABMQ6AEIMjAC\#v=onepage\&q=lilin\%20leb ah\&f=false. Diakses 14 Desember 2018.

Andi Aldi Matoro Putra. Dkk. 2014. Pemanfaatan Kulit Jeruk Bali (citrus maxima) Dan Serai (cymbopogon nardus) Sebagai Bahan Dasar Mat Obat Nyamuk Elektrik Yang Aman Bagi Kesehatan. Program Kreatiftas Mahasiswa. Universitas Tadulako. Palu. (online). andialdiempe.blogspot.com/2014/03/pemanfaatan-kulit-jeruk-bali-citrus.html. Diakses 20 Desember 2018.

Arda Dinata. 2018. Kesehatan Lingkungan. Yogyakarta: Nuha Medika.

Dantje T Sembel. 2009. Entomologi Kedokteran. Yogyakarta: Andi.

Dayat Suryana. 2018. Manfaat Buah: Manfaat Buah-Buahan.Bandung:Dayat Suryana Independent. (online). https://books.google.co.id/books?id=MuR0DwAAQBAJ. Diakses 13 Desember 2018. 